\title{
Rainfall Anomaly Index Valuation of Agricultural Production in Jakiri Sub- Division, Northwest Region, Cameroon
}

ISSN: 2637-7659

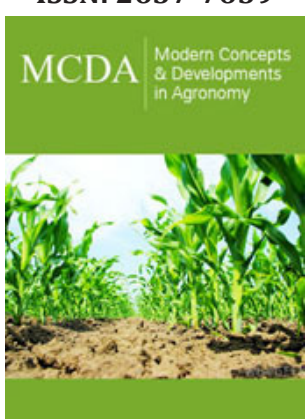

*Corresponding author: Suiven John Paul Tume, Department of Geography and Planning, The University of Bamenda, Cameroon

Submission: 㘹 May 06, 2021

Published: 㧫 September 22, 2021

Volume 9 - Issue 4

How to cite this article: Suiven John Paul Tume, Suika Rita Nyuyfoni. Rainfall Anomaly Index Valuation of Agricultural Production in Jakiri Sub-Division, Northwest Region, Cameroon. Mod Concep Dev Agrono. 9(4). MCDA. 000717. 2021. DOI: 10.31031/MCDA.2021.09.000717

Copyright@ Suiven John Paul Tume. This article is distributed under the terms of the Creative Commons Attribution 4.0 International License, which permits unrestricted use and redistribution provided that the original author and source are credited.

\author{
Suiven John Paul Tume* and Suika Rita Nyuyfoni \\ Department of Geography and Planning, The University of Bamenda, Cameroon
}

\begin{abstract}
Climate variability and change is one of the greatest threats facing humanity, with far-reaching and devastating impacts on people, ecosystem services, natural resource-base and the natural environment as a whole. This paper aims to evaluate the impact of rainfall variability on agricultural production in Jakiri Sub-Division of the Northwest Region of Cameroon. Previous studies on the impact of climate on agriculture focused on stakeholder signatures to climate change adaptation to the agrarian sector of the Bui Plateau, which revealed that despites glaring consequences of climate, the Jakiri Council only allocates only $1 \%$ of its annual budget for climate action. Data sources for this study included the administration of 211 questionnaires to cover the three agro-ecological zones of Jakiri Sub-Division, rainfall data collected from UNVDA Ndop (lowland zone), National Meteorological Service (mid-altitude zone) and the Oku Wildlife Sanctuary (highland zone). The Rainfall Anomaly Index (RAI) was used in analysing rainfall data. Results revealed that rainfall is reducing as depicted by the increasing trends in RAI. Farmers also perceived that food crop production has been decreasing. Despite these perceptions, some crops like cassava that is drought tolerant has been increasing. Again, rice production at the Wahsi-Ber Plain has been increasing. This calls for the development and production of more drought tolerant food crops to ensure sustainable rural livelihoods.
\end{abstract}

Keywords: Food crops; Rainfall; Vulnerability

\section{Introduction}

Climate variability and change is one of the greatest threats facing humanity, with farreaching and devastating impacts on people, ecosystem services, natural resource-base and the natural environment as a whole [1]. Climate stresses the food system from land preparation, growing of crops till the produced food reaches the final consumers. Agriculture on the other hand contributes to climate variability and change through emission of Greenhouse gases from poor farming techniques like slash and burn [2]. Climate variability and change has adverse physiological effects on crops through inadequate water, when available water cannot meet crop requirements at various critical stages such as germination, flowering and maturity [3]. Inadequate crop water during the growth stage makes crops vulnerable to pests and diseases attacks [4].

Most Sub-Saharan African countries are vulnerable to the effect of climate variability and change due to high reliance on rain-fed agriculture and natural resources, which constitute large part of local livelihoods [5,6]. Agriculture contributes about $70 \%$ of the GDP of some African economies $[7,8]$. Climate variability is projected to reduce yields from rain-fed agriculture by up to $50 \%$ by 2020 for some of the countries in Africa [9]. In Cameroon, mean annual rainfall has decreased by about $2.9 \mathrm{~mm}$ per month (2.2\%) per decade since 1960 [10]. Cameroon experienced particularly low rainfall in 2003 and 2005. Rainfall has continued to dwindle since 2010 [11]. Human activity has caused a variety of changes in different forcing 
agents in the Bamenda Highlands, where Jakiri Sub-Division is located.

Previous studies on the impact of climate on agriculture focused on stakeholder signatures to climate change adaptation to the agrarian sector of the Bui Plateau. In this paper, Tume et al. [12] revealed that despites glaring consequences of climate and environmental change like overgrazing, bush fires, water scarcity and increasing temperature, the Jakiri Council only sensitizes farmers on the dangers of their actions. These authors also revealed that the Jakiri Council allocates only $1 \%$ of its annual budget for climate action. Again, Tani et al. [13] focused on the role of municipal councils in climate change mitigation in the Northwest Region of Cameroon. The authors revealed that municipal authorities are more interested in enriching their pockets and bank accounts rather than taking climate action that affects poor rural farmers. This paper shows how such administrative lapses indirectly have accelerated the vulnerability of crop production to climate variability and change in Jakiri Sub-Division.

Several characteristics and indices are used in assessing rainfall variability. Some include inter-annual rainfall, rainfall seasonality, rainfall Coefficient of Variation, Standardized Precipitation Index (SPI) and many others (World Meteorological Organization (WMO) and Global Water Partnership (GWP) [14]; Tume et al. [15]. In this paper, the Rainfall Anomaly Index (RAI) is used, and it portrays episodes of extreme rainfall (floods) and meteorological droughts which affect crop production in Jakiri Sub-Division. In this light, this study falls within the context of the current global development agenda as addresses some global development goals, viz, SDG 2: end hunger, achieve food security and improved nutrition and promote sustainable agriculture, SDG 13: take urgent action to combat climate change and its impacts.

\section{Method of Study}

Jakiri Sub-Division is found Bui Division of the Northwest Region of Cameroon and has an estimated population of 194,088 (Jakiri Council, 2012), distributed in 58 villages. The main activity of this municipality is agriculture which takes place in different agroecological zones. The lower frontier is an extension of the Ndop plain, while the upland area is part of the Kilum-Ijim mountain forest. The area lies approximately on latitude 6 o $\mathrm{N}$ of the equator and longitude $10^{\circ} \mathrm{E}$ of the Greenwich Meridian (Figure 1). It has an altitude of about $1,700 \mathrm{~m}$ above sea level and a surface area of about $675 \mathrm{~km}^{2}$ (Jakiri Council, 2012). The area is bounded to the North by Kumbo, West by Elak-Oku, South by Babessi, to the SouthEast by Bangorain in the West Region and to the East by Mbiame. The area is made up Jakiri town at the centre constituting the main centre for commercial and administrative functions, Vekovi, Nkar, Sop, Wainamah, Yer, Shiy which act as nodes where growth and development could proceed and a host of other villages such as Mbokijah, Mbokam, Ber, Mantum, Wahsi, Rontong, Kinsenjam, Limbo, Kwanso, Ndzerem Nyam, Ntohti, Sarkong amongst others. Jakiri Sub-Division is structured into three agro-ecological zones, namely: the low altitude, the transitional and the high-altitude. This partition is because of the climatic and altitudinal characteristics which vary over the geographical space, thus, giving a notion that these zones portray different climatic characteristics. Rainfall incidence across these agro-ecological zones is not uniform, which in turn determines agricultural productivity in the area.

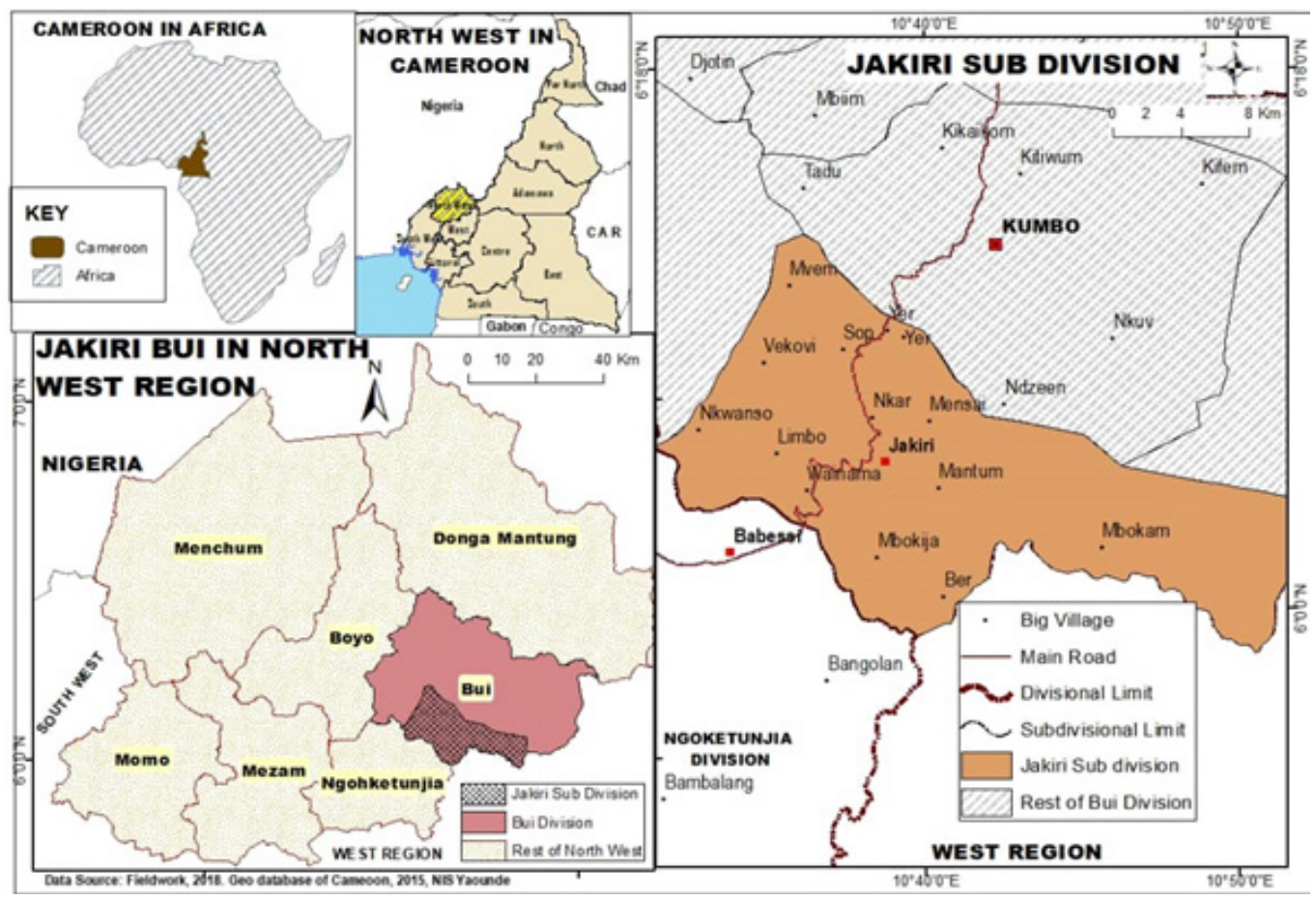

Figure 1: Location of Jakiri Sub-Division. Source: Jakiri Council, 2012. 
Primary sources of data collection used field observations and the administration of questionnaires. Field visits were undertaken at Wahsi-Ber rice fields, Mbokam and Limbo cassava production basins and Tan farming areas. The questionnaire was designed to capture farmers' perception of climate variability and changes in crops. The purposive sampling used was important because it permitted the researcher to reach out to those who have lived in Jakiri Sub-Division for at least 20 years as they were capable to give reliable information on rainfall variability. A total of 211 questionnaires were administered to farmers (Table 1).

Table 1: Distribution of questionnaire according to agroecological zones.

\begin{tabular}{|c|c|c|}
\hline $\begin{array}{c}\text { Agro-Ecological } \\
\text { Zones }\end{array}$ & Total Population & $\begin{array}{c}\text { Questionnaires } \\
\text { Administered }\end{array}$ \\
\hline Lowland & 49,952 & 39 \\
\hline Mid-altitude & 97,708 & 77 \\
\hline Highland & 46,428 & 95 \\
\hline Total & 194,088 & 211 \\
\hline
\end{tabular}

These questionnaires were age selective, to farmers from all age groups so as to obtain diverse and concrete information in order to understand rainfall variability and its implications on crop productivity. Some farmers groups also provided data on approximate cassava production from 1990-2018.

The independent variable for this study is climate and the element of climate considered for the study is rainfall. Rainfall data were obtained from the Upper Nun Valley Development Authority (UNVDA) Ndop (1990-2018), which has the same climatic characteristics of the lowland ecological zone. Rainfall data for the mid-altitude ecological zone (Jakiri) was obtained from the National Meteorological Service, Bonanjo-Douala (1961-2018), while data for the highland ecological zone was obtained from the Mount Oku Wildlife Sanctuary (1986-2018), which has the same ecological characteristics as Vekovi and its environs. Other secondary data sources included the UNVDA statistics on rice production for the Wahsi-Ber plain and data on cassava production from farmers groups in Mbokam and Limbo. Variations in rainfall were treated as anomalies to establish trends, illustrated in graphs, fitted with R2 and linear equations (Coefficient of Determination to show the percentage change). The climatic index used in this paper is Rainfall Anomaly Index (RAI), designed by van Rooy (1965). It considers the rank of the precipitation values to calculate positive and negative rainfall anomalies using the following equations:

$$
\begin{aligned}
& \text { RAI =+3 (RF-MRF)/(MH10-MRF) (Positive anomalies) } \\
& \text { RAI=-3 (RF-MRF)/(ML10-MRF) (Negative anomalies) }
\end{aligned}
$$

Where:

\section{RAI=the rainfall anomaly index}

$\mathrm{RF}=$ the rainfall for the year in question

$\mathrm{MRF}=$ the mean actual annual rainfall for the total length of the period
MH10 and ML10=the mean of 10 highest and lowest values of rainfall (RF) respectively of the period

RAI is dimensionless and it has also been used to determine variation in rainfall for the three agro-ecological zones in Jakiri Sub-Division. The RAI classification is used to determine extremes condition of rainfall in a particular area for decadal and annual time frames. The results gotten from the range and class description determine the variation in rainfall for that region which may be negative or positive. This range is from $\geq 3.0$ (extremely wet) to $\leq-3.00$ (extremely dry) (Table 2).

Table 2: RAI classification.

\begin{tabular}{|c|c|}
\hline RAI Range & Class Description \\
\hline$\geq 3.0$ & Extremely wet \\
\hline 2.00 to 2.99 & Very wet \\
\hline 1.00 to 1.99 & Moderately wet \\
\hline 0.50 to 0.99 & Slightly wet \\
\hline 0.49 to -.49 & Near normal \\
\hline-0.50 to -0.99 & Slightly dry \\
\hline-1.00 to -1.99 & Moderately dry \\
\hline-2.00 to -2.99 & Very dry \\
\hline$\leq-3.00$ & Extremely dry \\
\hline
\end{tabular}

\section{Source: van Rooy, 1965.}

RAI normalized precipitation values are based on weather history of a particular location. The only input parameter is precipitatio0n. It addresses agricultural and meteorological droughts that affect agriculture, water resources and other sectors. RAI is flexible in that it can be analysed at various timescales (World Meteorological Organization-WMO, 2016). It is easy to calculate, with a single input (precipitation) that can be analysed on a monthly, seasonal and annual timescale. For this study, the annual time scale is used. RAI classification ranges from $\geq 3.0$ (extremely wet) to $\leq-3.00$ (extremely dry). These extreme conditions are not favourable for rain-fed tropical crop production because extreme wetness is associated with flooding that destroys agricultural land, while extreme dry conditions are associated with severe water deficits that cannot support agricultural production. Positive anomalies have their values above the average and negative anomalies have their values below the average. Trend lines were fitted on the anomaly graphs to show changes in rainfall over time. The rainfall Standard Deviation (SD) and Coefficient of Variation (CV) were also calculated to show rainfall reliability. CV is calculated thus:

$$
\begin{aligned}
& \sigma=\llbracket \sqrt{ }(\Sigma(Y-\bar{Y})) \rrbracket^{\wedge} 2 / \mathrm{N} \\
& C V=\sigma^{*} 100 / \bar{Y}
\end{aligned}
$$

Where: $\bar{\Upsilon}=$ mean

$$
\sigma=\text { Standard deviation }
$$

$\mathrm{N}=$ sample size (number of years of available rainfall data) 


\section{Result}

\section{Farmers perception of rainfall variability}

Rainfall variability is perceived differently by different persons in different dimensions and localities. Since perception is a function of educational level, longevity in agricultural practice and gender in all the three agro-ecological zones of Jakiri, it was obtained that $65.9 \%$ of the sampled population have lived in the study area for more than 20 years, whereas $57.3 \%$ were male and $42.7 \%$ female (Table 3).

Table 3: Agro-ecological zones, duration of stay and gender of sampled population.

\begin{tabular}{|c|c|c|}
\hline Variables & Frequency & Percentage \\
\hline \multicolumn{3}{|c|}{ Agro-ecological zone } \\
\hline Wahsi-Ber-Mbokam & 39 & 18.5 \\
\hline Jakiri-Nkar-Sop & 77 & 36.5 \\
\hline Kisenjam-Vekovi & 95 & 45 \\
\hline Total & 211 & 100 \\
\hline \multicolumn{3}{|c|}{ Duration of stay } \\
\hline $6-10$ years & 19 & 9 \\
\hline $16-20$ years & 53 & 25.1 \\
\hline 20 years+ & 139 & 65.9 \\
\hline Total & 211 & 100 \\
\hline \multicolumn{3}{|c|}{ Gender } \\
\hline Male & 121 & 57.3 \\
\hline Female & 90 & 42.7 \\
\hline Total & 211 & 100 \\
\hline
\end{tabular}

Source: Fieldwork, July 2019.

Table 4: Farmers perception on rainfall variability.

\begin{tabular}{|c|c|c|}
\hline Perception & Frequency & \% \\
\hline Prolonged dryness and longer dry season & 192 & 91 \\
\hline Decease rainfall & 167 & 79.1 \\
\hline Increase rainfall & 132 & 64.5 \\
\hline Shorter rainy season & 149 & 70.6 \\
\hline Loss of crops seems to be on the increase & 43 & 24.5 \\
\hline
\end{tabular}

Source: Fieldwork, July 2019.

Rainfall variability means different things to indigenous farmers. Some attribute it to prolonged dry season (91\%), others to shorter rainy season $(70.6 \%)$, some perceived a decrease in rainfall $(64.5 \%)$ while $(79.1 \%)$ have a perception that there is an increased in rainfall (Table 4).

It should be noted that these responses on farmers' views about their personal perception of rainfall in the all the three agroecological zones is a function of the socio-demographic correlates. Only $24.5 \%$ of the farmers in the different agro-ecological zones were neutral and had no idea of what is happening to rainfall but believe that their variation. In an interview with a 59-year-old farmer (man) in Wahsi, he affirmed that 'yes I believe there is rainfall variability, but I have no idea of what is really causing it'.

\section{Actual rainfall variability within the Jakiri ecological zones}

There exists variation in rainfall in the different agro-ecological zones of Jakiri Sub-Division. Different crops cultivated reflect the different agro-ecological zones of Jakiri as determined by rainfall and soil moisture. The high altitude agro-ecological zone (Vekovi, Nkarkui, Kisenjam) experiences more rainfall. The mean annual rainfall here is about $171.3 \mathrm{~mm}$. Minimum rainfall occurs from December to March (dry season). Maximum rainfall is recorded in the months of June to September. The lowland areas especially those on valley sides and on the upper edge of the Ndop plain such as Ber, Wahsi and Tan (part of the hollow frontier ecological zone) located on south-eastern part of the Sub-Division has less rainfall comparable to the high-altitude zone. Here, mean annual rainfall is $158 \mathrm{~mm}$. This transitional ecological zone has mean annual rainfall of $165.74 \mathrm{~mm}$. Like the other ecological zones, lowest amounts of rainfall are recorded in December to March, while high amounts are recorded from June to September. This variation reveals that rainfall decreases with increase in altitude in the Jakiri agroecological zones

\section{Inter-annual rainfall variability}

In order to examine spatial variation of rainfall incidence in the three agro-ecological zones of Jakiri, the rainfall Standard Deviation, Coefficient of Variation and the RAI have been used. The lowland agro-ecological zones have rainfall characteristics similar to those of the Ndop plain. The inter-annual rainfall anomaly graph was used to show the trend of rainfall variation for a period 28 years (1990-2018) (Figure 2).

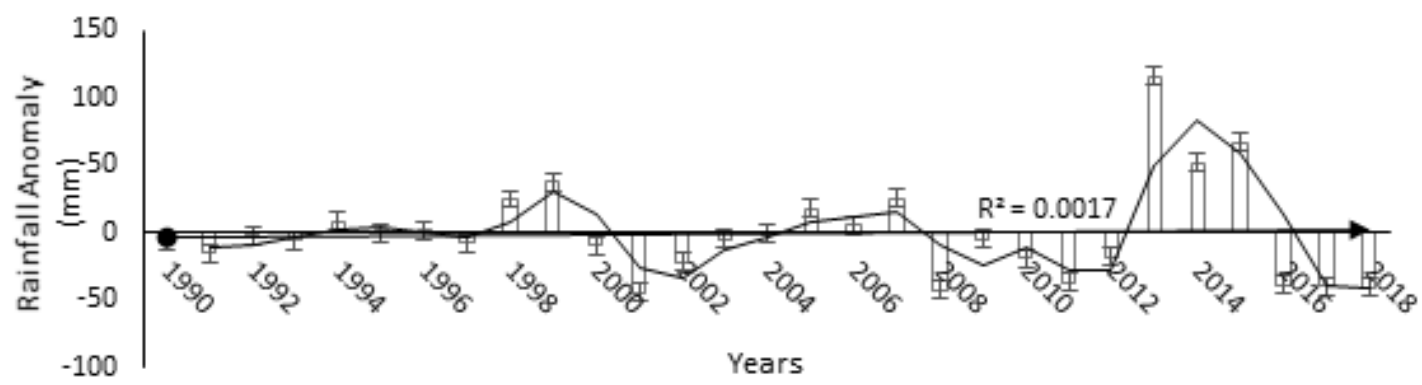

Figure 2: Inter-annual rainfall anomaly for lowland ecological zone. Data source: UNVDA, Ndop, (2018). 
Inter annual rainfall in the lowland agro-ecological zone shows slight fluctuations. The rainfall trend for this lowland ecological zone depicts a slight increase with a coefficient of determination (R2) of $0.0017(0.17 \%)$. It is noted that the highest rainfall amount measured was in 2013 around $(125 \mathrm{~mm})$ and the lowest in 2001 $(-45 \mathrm{~mm})$. The rainfall standard deviation here is 34.65 , with a Coefficient of Variation of $21.93 \%$ (unreliable because it more than the tropical threshold of 20\%). The rainfall for the transitional or mid latitude agro-ecological zone presents a different situation from the lowland ecological zone. Rainfall pattern is not evenly distributed in the two agro-ecological zones. Each zone is delimited depending on rainfall characteristics of the zone. The rainfall data used in this zone ranges from 1961-2018 (Figure 3).

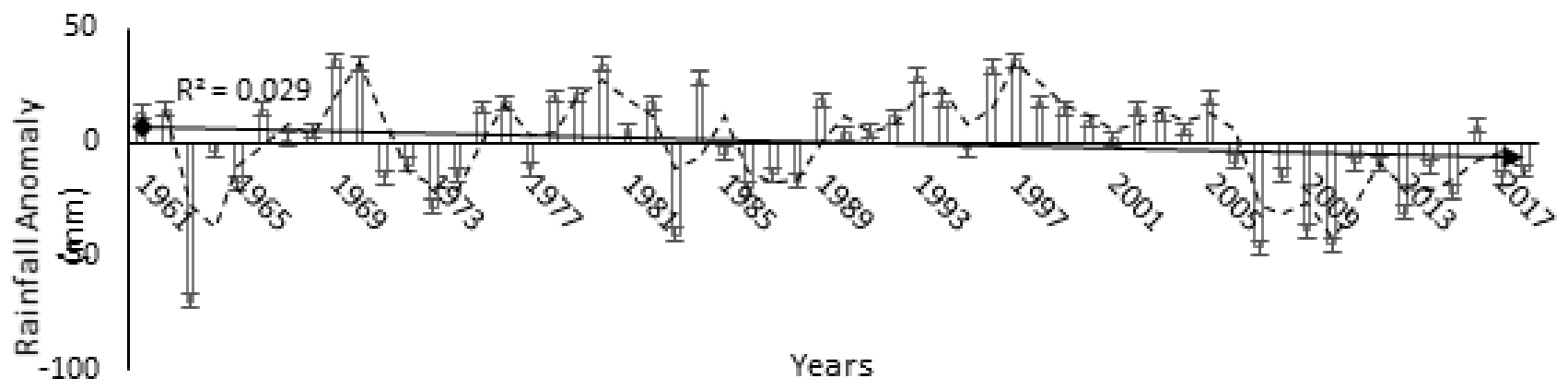

Figure 3: Inter-annual rainfall anomaly for mid-altitude ecological zone.

Data source: National Meteorological Service, (2018).

The results revealed that the $\mathrm{R} 2$ is 0.029 and representing a $2.9 \%$ decrease. This depicts a decreasing trend in the inter-annual rainfall of the mid-altitude agro-ecological zone. The years 1963, 1983, 2006 and 2010 recorded very low rainfall. This could be attributed to prolonged dry spells and irregular onset of the first rains and early cessation of the rains. The standard deviation here stands at 22.9, with Coefficient of Variation of 13.81\% (reliable). The highland ecological zone is situated on the highland extension of the Kilum-Ijim mountain forest. There has been general notion that rainfall in this zone is heavier as compared to two previous agro-ecological zones. The rainfall data used in this zone range from 1986-2018, (Figure 4).

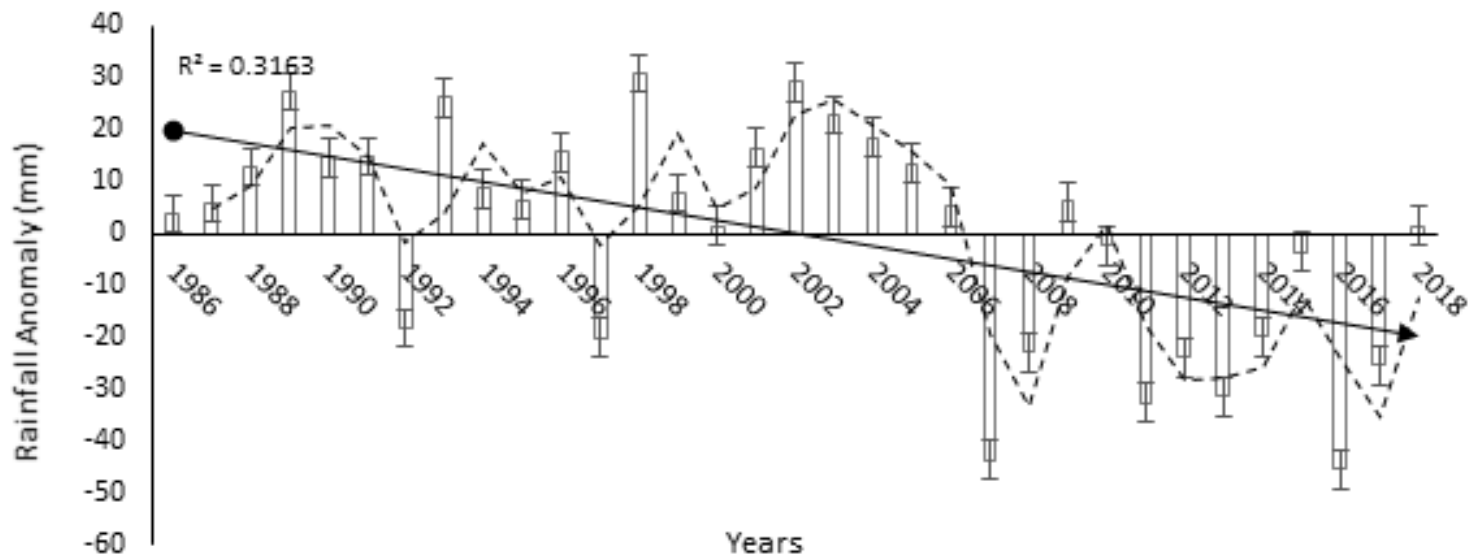

Figure 4: Inter-annual rainfall anomaly for highland ecological zone.

Data source: Kilum Wildlife Sanctuary, 2018.

The inter-annual rainfall coefficient of determination for the highland ecological zone (R2=0.3163) depicts a $31.63 \%$ drop in rainfall. From the analysis, this zone experienced increasing rainfall from 1986-2005, but there has recently been a drastic decline in rainfall for the past 10 years (2008-2018). This means that the high altitude is noted for heavy rainfall is gradually changing because results we have is a negative trend. Note is also taken that the amount of rainfall in $\mathrm{mm}$ is showing a negative with the $(-55 \mathrm{~mm})$ in 2016. The standard deviation here is 21.38 and a Coefficient of Variation of $12.48 \%$.

The rainfall standard deviation (SD) and Coefficient of Variation (CV) are also used to determine rainfall variability in the three agroecological zones. The mean annual rainfall as well as the maximum and minimum rainfall for the three stations representing each agroecological zone has been calculated in order to show more impetus in variation (Table 5). 
Table 5: Rainfall standard deviation and coefficient variation.

\begin{tabular}{|c|c|c|c|c|c|c|}
\hline Station & MAR (mm) & Min $(\mathbf{m m})$ & Max $(\mathbf{m m})$ & SD & CV (\%) & Remark \\
\hline Ndop & 153.43 & 127.85 & 202.17 & 34.65 & 21.93 & Unreliable \\
\hline Jakiri & 165.74 & 119.33 & 201.9 & 22.9 & 13.81 & Reliable \\
\hline Oku & 171.3 & 112.6 & 269.47 & 21.38 & 12.48 & Reliable \\
\hline
\end{tabular}

MAR: Mean Annual Rainfall, SD: Standard Deviation, CV: Coefficient of Variation.

Source: Calculated from climatic data for the three ecological zones.

The value of $\mathrm{CV}$ has limits of reliability and unreliability. When $\mathrm{CV}$ is $\leq 20$ it means that rainfall variability reliable but when $\geq 20$ it indicates unreliable. Hence, rainfall is unreliable for the lowland ecological zone (21.93\%), and reliable for the mid-altitude and highland ecological zones respectively with values of $13.81 \%$ and $12.48 \%$. The data used to determine variation in the lowland ecological zone was obtained from the Ndop plain since its share similar climatic characteristics with the hollow frontier agroecological zones. In order to analyze the RAI, the trend line in the graph determines if each agro-ecological zone is experiencing rainfall deficits or surplus (Figure 5).

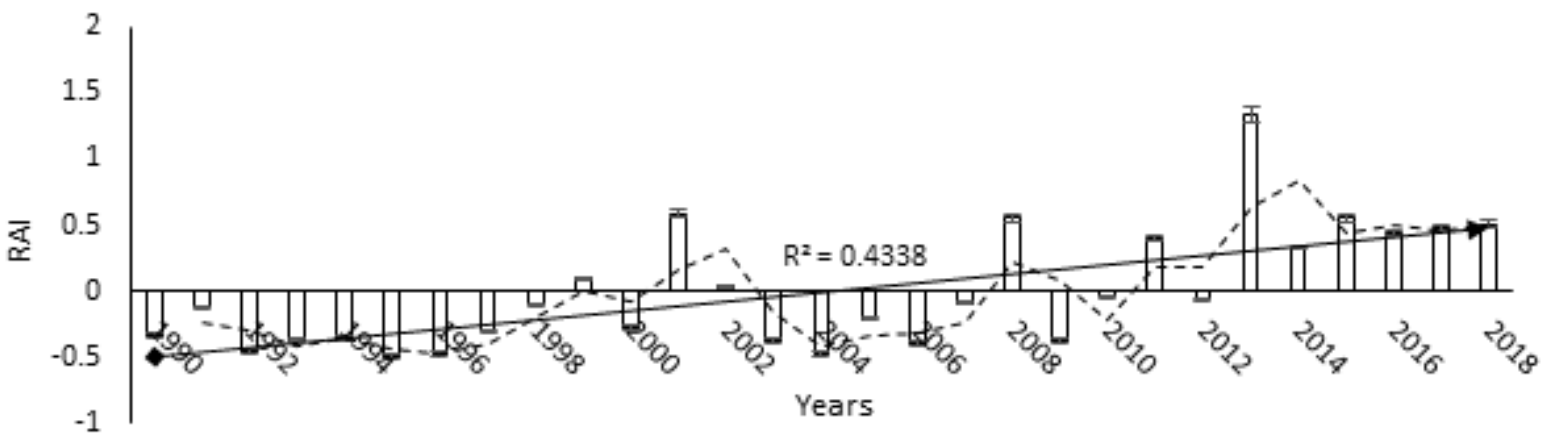

Figure 5: Rainfall Anomaly Index for Ndop (1990-2018).

From 1990-1998 the zone experienced dryness with the highest recorded between 1995 and 1996 with (-0.5). This indicates a slightly dry from the RAI classification table (-0.5 to -0.99). In 1990 a slight increase in the RAI ( 0.1 ) but drops to the -0.2 the following year. From 2002-2007 RAI was still negative. The situation in 2008 shows a 0.5 RAI meaning the year was slightly wet. The rainfall anomaly index of the mid-attitude is agro-ecological zone is analyzed using data collected from 1961-2017 (56 years) (Figure $6)$.

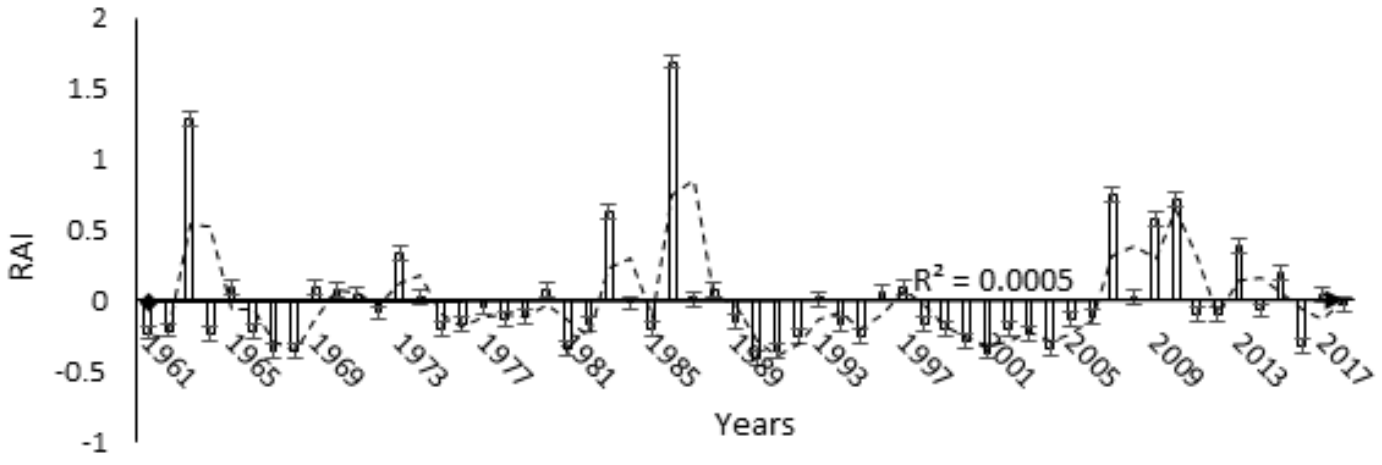

Figure 6: Rainfall Anomaly Index for Jakiri (1961-2018).

There is variation in rainfall throughout the area. These negatives values range between $(-0.1$ to -0.5$)$ which indicate slight dryness. Looking at the positive values rainfall has not been evenly distributed annually there are years that recorded high rainfall than others. In 1963 after the dryness in the two previous years 1.3 RAI was recorded signifying a moderately wet year. This zone also experienced slightly wet years from 1970-1971. In 1974 and
1982 the trend was increasing up to 1986 where the highest year of moderately wet (1.7) was recorded. Moreover, in the years 2007, 2010, 2011, 2014, 2016 the zone has been slightly wet. Essentially the trend line determining the variation using RAI is just slightly above average or zero which is signifying slightly dryness. Data obtain for this analysis is records for the past 32 years analyzing rainfall anomaly for the high-altitude zone (Figure 7). 


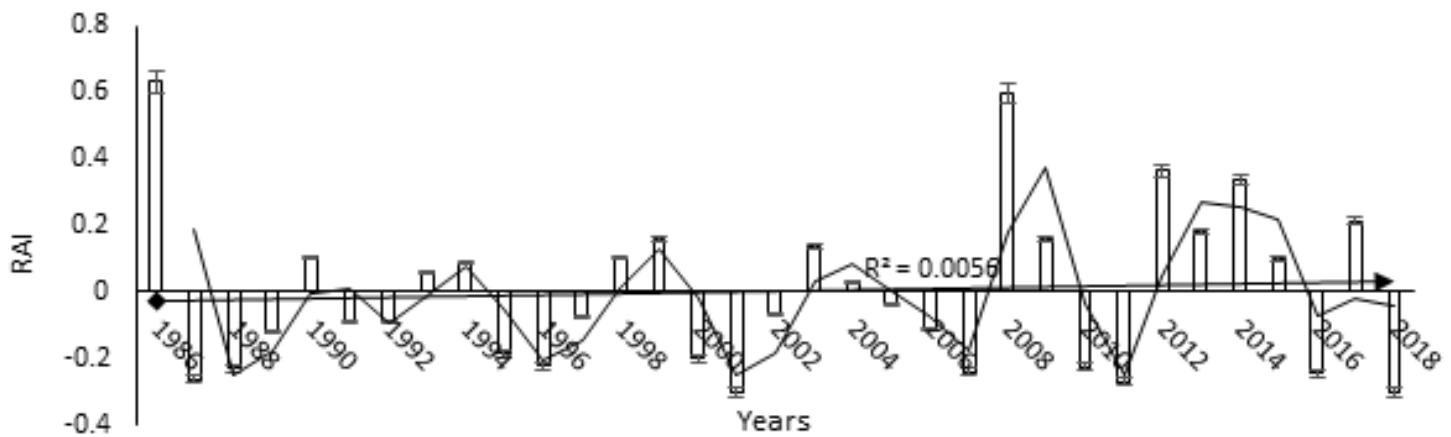

Figure 7: Rainfall Anomaly Index for Oku (1986-2018).

The time series shows inter annual rainfall fluctuation which is a usual phenomenon for all the zones. Fluctuation between the negatives and positives values of RAI throughout is between slightly wet or slightly dry meaning this zone is only liable to wetness rainfall variation which are not close to extremes events of water deficits drought and floods. The highest positive values of
RAI (0.6) recorded were in 1986 and 2008. While the lowest RAI of (0.6) was recorded in 1996 and 2018. With variations in rainfall conditions, RAI trends are increasing, suggesting that rainfall is gradually reducing in the ecological zones. It has been discovered that rainfall in the low altitudes zone is reducing more as compared to the mid and high-altitude zones (Table 6).

Table 6: Summary of decadal RAI for Jakiri Sub-Division.

\begin{tabular}{|c|c|c|}
\hline Decades & RAI Class Descriptions & Number of Incidents \\
\hline \multicolumn{3}{|c|}{ Lowland Ecological Zone } \\
\hline \multirow{3}{*}{ 1990-1999 } & Slightly dry & 9 \\
\hline & Near normal & 1 \\
\hline & Slightly dry & 7 \\
\hline \multirow{3}{*}{$2000-2009$} & Slightly wet & 2 \\
\hline & Near normal & 1 \\
\hline & Slightly dry & 2 \\
\hline \multirow{2}{*}{$2010-2018$} & Moderately wet & 1 \\
\hline & Near normal & 6 \\
\hline \multicolumn{3}{|c|}{ Mid-Altitude Ecological Zone } \\
\hline \multirow{4}{*}{$1961-1970$} & Slightly dry & 6 \\
\hline & Slightly wet & 3 \\
\hline & Moderately wet & 1 \\
\hline & Slightly dry & 6 \\
\hline \multirow{2}{*}{$1971-1980$} & Slightly wet & 4 \\
\hline & Slightly dry & 6 \\
\hline \multirow{3}{*}{$1981-1990$} & Slightly wet & 3 \\
\hline & Moderately wet & 1 \\
\hline & Slightly dry & 7 \\
\hline \multirow{2}{*}{$1991-2000$} & Near normal & 3 \\
\hline & Slightly dry & 6 \\
\hline \multirow{3}{*}{$2001-2010$} & Slightly wet & 3 \\
\hline & Near normal & 1 \\
\hline & Slightly dry & 3 \\
\hline \multirow{2}{*}{ 2011-2018 } & Slightly wet & 1 \\
\hline & Near normal & 4 \\
\hline \multicolumn{3}{|c|}{ Highland Ecological Zone } \\
\hline \multirow{3}{*}{ 1986-1996 } & Slightly dry & 7 \\
\hline & Slightly wet & 1 \\
\hline & Near normal & 3 \\
\hline
\end{tabular}




\begin{tabular}{|l|c|c|}
\hline \multirow{2}{*}{$1997-2007$} & Slightly dry & 7 \\
\cline { 2 - 4 } & Near normal & 4 \\
\hline \multirow{2}{*}{$2008-2018$} & Slightly dry & 4 \\
\cline { 2 - 4 } & Slightly wet & 7 \\
\hline
\end{tabular}

Source: Source: Calculated from climatic data.

These characteristics reveal that there have been 63 incidents of slightly dry conditions, 23 near normal episodes, 24 slightly wet incidents and 3 moderately dry instances. Slightly dry and moderately dry episodes are periods of meteorological droughts.
From this data, the Jakiri agro-ecological zones have been prone to meteorological and agricultural droughts, which threaten food crop production and it is a threat to food security.

\section{Effects of rainfall variability on Jakiri agricultural production}

Table 7: Impacts of rainfall variability.

\begin{tabular}{|c|c|c|}
\hline Impacts & Frequency & \% \\
\hline Decrease and drying water sources & 166 & 58.7 \\
\hline Decreased in crop output & 124 & 91 \\
\hline Pests and crop diseases & 192 & 81 \\
\hline Soil erosion & 171 & 38.4 \\
\hline Floods occurrences & 81 & 76.3 \\
\hline Livestock diseases have increased & 161 & 48.8 \\
\hline Increased livestock mortality & 103 & 54 \\
\hline
\end{tabular}

Source: Fieldwork, July 2019.

Variations in rainfall in the study area is being felt by farmers because of the impacts it has on productivity. It is because of these abnormality in the intensity and duration of rainfall that either leads to extremes and slight extremes events of rainfall characteristics. The occurrences of floods, dry spells, soil erosion reduction in water sources gives us the impression that rainfall varies over time and space. The highest problem affecting productivity is pest and crop diseases (91\%), followed by soil erosion (81\%), and then decrease and drying water bodies (79\%) (Table 7).

Soil erosion is very common in all the zones but highest in the high-altitude zone because it's a steep slope and any intensive rainfall washes the soils away downward rendering the farms with less nutrients. On the other hand, the low altitude zones experienced floods in the rainy periods since most streams convey around there. The overflow waters into farmlands destroys crops. This is worse when crops are still in an early stage of growth. Prolonged dry season and dryness reduces the water table of most rivers and renders some streams dry. That is why irrigation farming is only limited around Ber and Washi. Rainfall is the key determining factor of crop production in Jakiri Sub-Division since crop cultivation is rain-fed dependent. Less rainfall in terms of duration reduces the growing season. This in turn determines crop's ability to resist dry spells. Unpredictable annual oscillation in rainfall causes to crop destruction. Less rainfall in terms of intensity contributes to failure in crops like maize and rice because they require much water for growth.

\section{Effects of rainfall variability on crop output}

Generally, the effects of rainfall variability on crop output depend on either excess or deficit in rainfall in other words climatic extremes of flood and dryness affects crop productivity and leads to the occurrences of other factors like dry spell, soil erosion which contributes to low productivity and later leads food shortage and insecurity in the study area (Table 8).

Table 8: Effects of rainfall variability.

\begin{tabular}{|c|c|c|}
\hline Effects & Frequency & \% \\
\hline Decrease in production & 117 & 55.5 \\
\hline Food insecurity & 57 & 27 \\
\hline Floods & 146 & 69.2 \\
\hline Prevalence crop pests and diseases & 179 & 84.8 \\
\hline Rising temperatures & 157 & 74.4 \\
\hline Long periods of dry spell after first rain & 209 & 74.9 \\
\hline High soil erosion and leaching & 158 & 83.9 \\
\hline Drying up of streams and springs & 155 & 73.5 \\
\hline Reduction in the volume of water in rivers and & 191 & 90.5 \\
\hline streams & 104 & 49.3 \\
\hline
\end{tabular}

Source: Fieldwork, July 2019.

The farmers perceive that the main effects of rainfall variability in Jakiri Sub-Division are decrease in production (55.5\%), emerging food insecurity (27\%), floods (69.2), prevalence of crop pests and 
diseases (84.8\%), rising temperatures (74.4\%), longer periods of dry spells after the onset of first rains (74.9\%), high soil erosion and leaching (83.9\%), drying up of streams and springs (73.5\%), reduction in the volume of water in rivers and streams (90.5) and prevalence of cultivator-grazier conflicts (49.3\%). The Wahsi and Ber plain is the only area where rice cultivation is carried out in
Jakiri Sub-Division. The agro-ecological zone has climatic conditions like the Ndop plain and support rice cultivation. Rice production in Wahsi-Ber plain has been increasing, despite variations in rainfall and environmental conditions. Data collected from the UNVDA in Ndop for this production basin show an increasing trend of $15.07 \%$ from 1983-2010 (Figure 8).

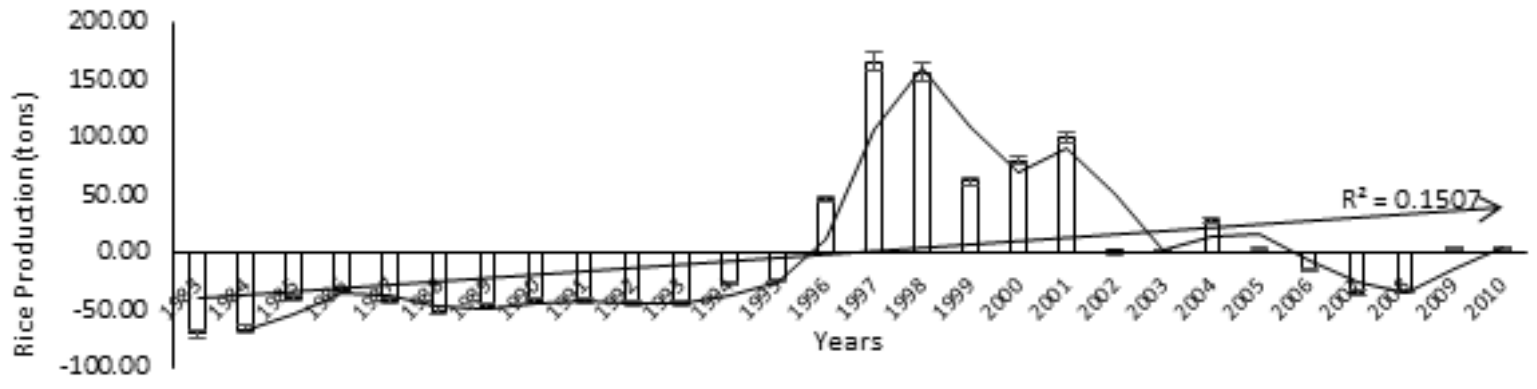

Figure 8: Rice production for Wahsi Plain. Data source: UNVDA, Ndop, 2010.

Rice production is increasing. From the year 1983-1995 the production was negative anomaly was to lack of interest in rice cultivation. From 1996 the trend line started increasing and with positive anomaly till 2001. From to $2002-2010$ has been positive fluctuation in rice productivity probably due to variation in rainfall.

\section{Farmer's perception of changes in crops output}

Farmers from the three agro-ecological zones has different perception about each variety of crop cultivated in each zone. There is either an increase, decrease, no change and not applicable for the cultivation of each crop species for the past years (Table 9).

Table 9: Perceived changes in crops and animal production.

\begin{tabular}{|c|c|c|c|c|c|c|c|c|}
\hline \multirow{2}{*}{ Crops } & \multicolumn{2}{|c|}{ Increase } & \multicolumn{2}{|c|}{ Decrease } & \multicolumn{2}{|c|}{ No change } & \multicolumn{2}{|c|}{ Not applicable } \\
\hline & $\mathbf{F}$ & $\%$ & $\mathbf{F}$ & $\%$ & $\mathbf{F}$ & $\%$ & $\mathbf{F}$ & $\%$ \\
\hline Maize & 95 & 45 & 97 & 46 & 19 & 9 & 0 & 0 \\
\hline Solanum potato & 94 & 44.5 & 78 & 37 & 39 & 18.5 & 0 & 0 \\
\hline Beans & 139 & 65.9 & 54 & 25.6 & 18 & 8.5 & 0 & 0 \\
\hline Groundnuts & 60 & 28.4 & 52 & 24.6 & 36 & 17.1 & 63 & 29.9 \\
\hline Cassava & 88 & 41.7 & 1 & 0.5 & 38 & 18 & 84 & 39.8 \\
\hline Cocoyam & 156 & 73.9 & 36 & 17.1 & 19 & 9 & 0 & 0 \\
\hline Yams & 91 & 43.1 & 47 & 22.3 & 73 & 34.6 & 0 & 0 \\
\hline Tomato & 132 & 62.6 & 1 & 0.5 & 40 & 19 & 38 & 18 \\
\hline Onion & 89 & 42.2 & 44 & 20.9 & 17 & 8.1 & 61 & 28.9 \\
\hline Soybeans & 26 & 12.3 & 54 & 25.6 & 70 & 33.2 & 61 & 28.9 \\
\hline Coffee & 59 & 28 & 125 & 59.2 & 27 & 12.8 & 0 & 0 \\
\hline Vegetables & 171 & 81 & 15 & 7.1 & 25 & 11.8 & 0 & 0 \\
\hline Market gardening & 102 & 48.3 & 1 & 0.5 & 19 & 9 & 89 & 42.2 \\
\hline Rice & 22 & 10.4 & 20 & 9.2 & 8 & 3.8 & 161 & 76.3 \\
\hline Cow peas & 100 & 47.4 & 56 & 26.5 & 36 & 17.1 & 19 & 9 \\
\hline Pineapple & 37 & 17.5 & 3 & 1.4 & 0 & 0 & 171 & 81 \\
\hline Plantain and egusi & 115 & 54.5 & 34 & 46.1 & 62 & 29.4 & 0 & 0 \\
\hline
\end{tabular}

F: Frequency. Source: Fieldwork, July 2019.

Crops like beans, vegetable, cocoyam's which show a positive change this is probably because they are applicable in all the agro-ecological zones, but maize which is the most applicable in the three zone is reducing in general productive of $1 \%$. The main food crops are cultivated in all the agro-ecological zones they include maize, beans, vegetable, solanum potatoes, plantain and egusi (pumpkin seeds). Beans, cocoyam, vegetables, plantain and egusi are increasing with a positive percentage change but a slight decrease in maize solanum potato and yams giving a negative percentage change (Figure 9). 


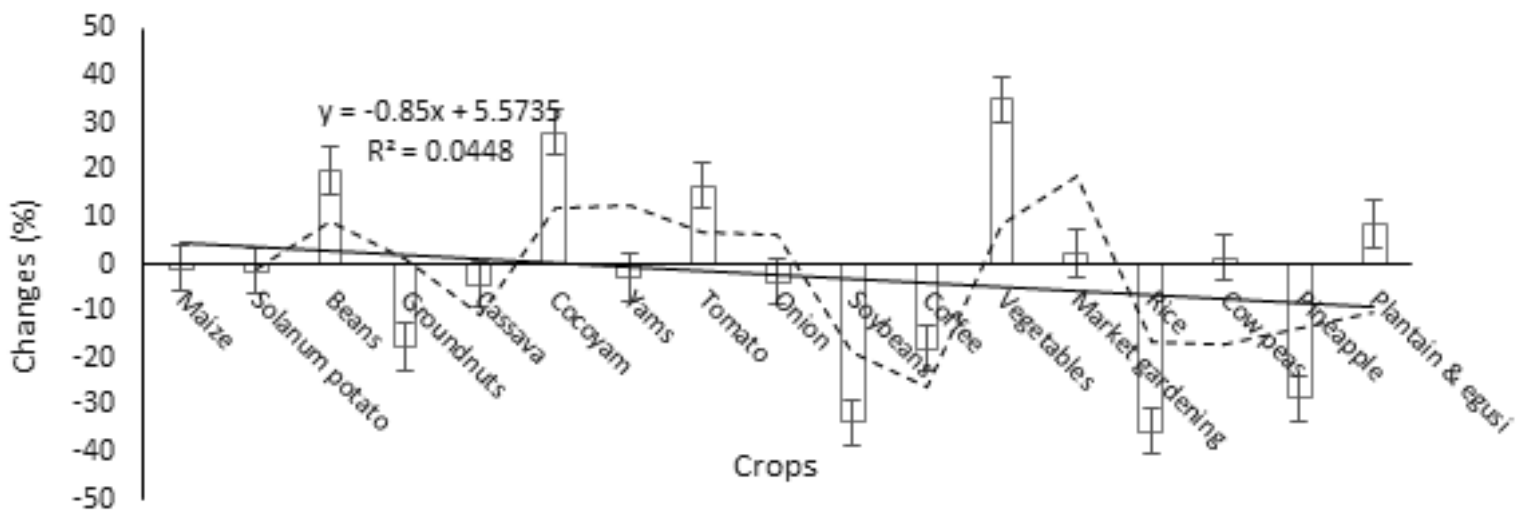

Figure 9: Perceived changes in food crop production in Jakir Sub-Division.

Source: Fieldwork, July 2019.

Cash crops are not cultivated in all zones. Rice and cassava are cultivated in the lower and transitional ecological zones, but rice shows a negative general percentage change because it is cultivated just in the lowland agro-ecological zone. The high-altitude zone is noted for market gardening and others. There is a general increase in cash crop in Jakiri Sub-Division. Most cash crops that are not applicable in all the three agro-ecological zones represent the lowest negative anomaly they include rice, soybeans, pineapple while cattle, vegetable, tomatoes and cocoyam have positive change. Despite the perceived decrease in groundnuts, field observation proved the contrary. The farmers also perceived that cassava production is on the decrease, but field observations and some secondary data proved otherwise. The main cassava production basins are in the lowland ecological zone. Data shows increasing trends for Mbokam and Limbo (Figures 10 \&11).

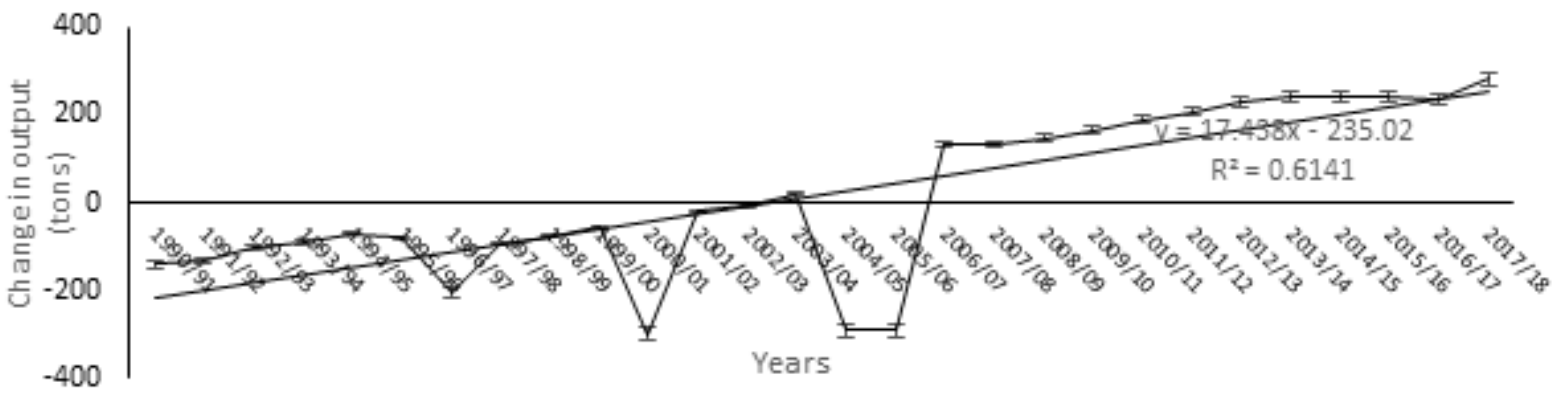

Figure 10: Cassava production trends for Mbokam.

Data source: Mbokam cassava farmers' groups (2019).

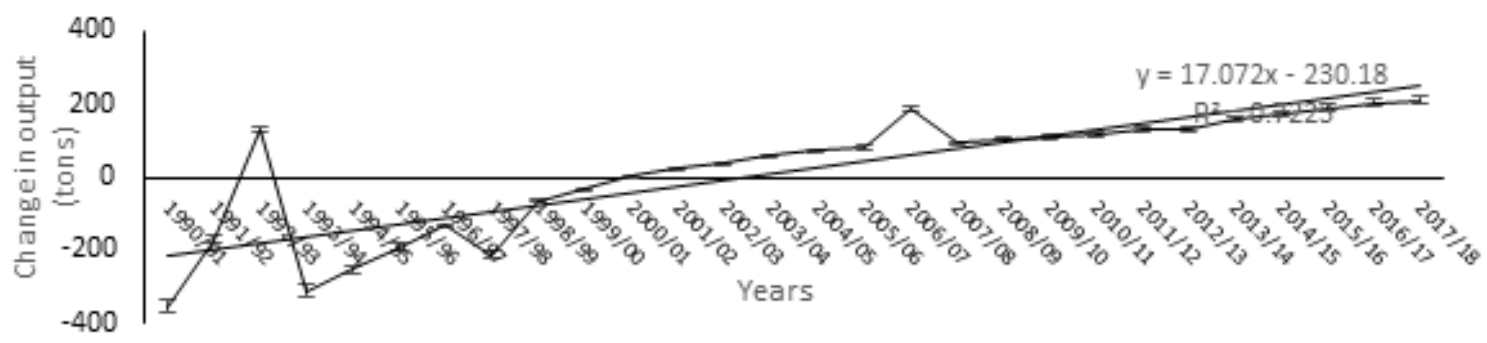

Figure 11: Cassava production trends for Limbo.

Data source: Limbo cassava farmers' groups (2019).

Note should be taken that all cash crops show a general decreased in their output, but field observation confirms an increased in productivity since these crops are grown only in specific zones. Farmers in Mbokam area have increasingly improved on cassava production in terms of areal coverage by extending farmlands just only for cassava rather than the old way of planting at farm boundaries. New species of cassava which have only a year life span to get mature is what farmers recently been cultivating and farming techniques. A mature cassava stand at fresh harvest is able to give approximately $8-15 \mathrm{~kg}$. Cassava is transformed into a number of by-products, such as cassava flour, starch and many others. All these by-products are meant for consumption and commercial purposes in local markets in Jakiri, Bui Division and beyond. Increased productivity of cassava is normal for reliable 
rainfall conditions of the lowland agro-ecological zones. Adverse climatic conditions have physiological effects on crops and livestock. Higher temperatures reduce water available for crops by drying out air and soils, while they increase pest and disease pressures, directly stress livestock. The physical harm to food production and the consequences for people will be greatest in the most foodinsecure regions, particularly in Sub-Saharan Africa where tens of millions of hectares of agricultural lands will become substantially drier. Populations in these regions (including Jakiri Sub-Division) already experience high rates of undernutrition, have limited or no social insurance, less government support and are most likely to experience direct health threats from extreme temperatures.

\section{Discussion}

Understanding and predicting temporal variations in African climate has become the major challenge facing African agriculture [16]. While seasonal climate forecasts have taken great strides forward, rural farmers remain unsure of the ultimate causes of the lower frequency decadal and multi-decadal rainfall variability that affects some African climate regimes, especially in the African savannahs (where Jakiri Sub-Division is located) [5]. Many socioeconomic activities in Africa heavily depend on climate and specifically on rainfall. The formal and informal economies of most African countries are strongly based on natural resources, especially agro-pastoralism [17]. Consequently, climatic variations alter the production systems of these activities have very high leverage on the local economy. It is estimated that on a global scale, about $75 \%$ of the natural disasters are associated with extreme weather and climate events such as floods and droughts, with devastating consequences on rain-fed agro-pastoral systems (like Jakiri SubDivision) [18]. Such extreme events increase the vulnerability of society to climate variability and change [4].

Climate variability and change has already impacted and will further impact the agriculture sector and food production. Sensitivity to climate as well as several to other driving forces, especially from the economic and societal domains, will determine the future evolution of the sector. But climate influence must be considered as a first-order factor in the context of the enormous challenge of providing food for about 8 billion people by 2,100 compared to the current 7.1 billion today [19]. Assessments of climate influence on crop functionality should consider stimulation of photosynthesis by the elevation of $\mathrm{CO}_{2}$ atmospheric concentration. The direct influence of climate variations on crop function evidently involves temperature, the effects of which may be quite variable. Higher temperatures are generally favourable for growth in cold climates (except in extreme events) and generally unfavourable for warm areas. Further warming has increasingly negative impacts in all regions [20].

On the other hand, rainfall variability seriously modulates the potential changes in plant growth resulting from the effects of increasing temperatures. Tendencies towards drier conditions in some areas such as the West and Southern of Africa may cancel, at least partially, the positive potential impact due to higher $\mathrm{CO}_{2}$ or milder temperatures [2]. Such combined climate influence leads to a variety of contrasted effects on crop production, depending upon the type, the geographical zone and the level of adaptation. Farmers' perceptions were recorded on changing crop pattern, with decreasing trends in food and cash crops [4].

The global projected temperature rise of $1.4-5.8{ }^{\circ} \mathrm{C}$ over the period 1990 to 2100 [21] will result in large changes in the frequency of extreme events which can have severe impacts on agriculture (Mathews et al., 2016). Increases in surface temperatures will increase soil temperatures which will in turn affect plant metabolism through the degradation of plant enzymes, limiting photosynthesis and affecting plant growth and yields [22]. Increases in soil temperature will also increase potential evapotranspiration which causes damage especially to those crops with surface root systems which utilize mostly precipitation moisture [21]. It increases leafsurface temperatures hence affecting crop metabolism and yields making crops more sensitive to moisture stress conditions. Such crops include groundnuts, soybeans, maize and fruit trees (all cultivated in the ecological zones of Jakiri Sub-Division) [23].

Blanc [24] revealed that crop yields change in 2100 will be near zero for cassava, $-19 \%$ to $+6 \%$ for maize, $-38 \%$ to $-13 \%$ for millet and $-47 \%$ to $-7 \%$ for sorghum under alternative climate change scenarios in SSA. Basic food stuff on which people live on daily have been declining in Jakiri Sub-Division and the Bui Plateau in general because food crop production systems are rain-fed [12,25]. When there is, thus, hydrological, meteorological or agricultural drought, threats to food security and crop failure will be evident [4]. Cassava has proven to be weather-proof and resilient to changing environmental conditions. It is grown almost throughout the year in Jakiri Sub-Division. According to Ajiere et al. [26], the new improved cassava stems harvesting is done 6 to 18 months after planting making it preferable to the seasonal crops of yams, beans or solanum potato.

Shifts in seasonal patterns, recurrent meteorological droughts and unpredictable precipitation affect crop yields and make some crops and varieties inviable, while extreme weather events, floods and other disasters destroy crops [27]. Climate variability and change also increases the incidence of pests and diseases. In the face of these environmental adversaries, switching to crop varieties that are resistant to heat, drought and/or floods, diversification of crops, irrigation, sustainable water management practices, climate-smart agriculture and regenerative farming techniques and practices, off-farm activities, crop insurance will go a long way to enhance farmers' resilience and adaptive capacity [4,8]. In addition to resilience, these endeavours can also create new business opportunities and equity funds to invest in agro-production and develop lending products tailored to smallholder and larger-scale agri-producers to invest in climate resilient farming practices [25].

\section{Conclusion}

There is still a slight increase in the inter-annual rainfall for the lowland agro-ecological zone, while mid and high-altitude areas are already witnessing significant drops in rainfall. The rainfall 
Coefficient of Variation (CV) revealed that rainfall is still reliable in the low and mid agro-ecological zones while the high zone is getting unreliable. The values are $21.93 \%, 13.81 \%$ and $12.48 \%$ for the lowland, mid-altitude and highland zones respectively. The main indices used to determine rainfall variability in Jakiri SubDivision is the Rainfall Anomaly Index (RAI). The RAI is increasing for all the ecological zones. An increasing RAI, show that dry spells are recurrent. Recurrent dry spell mean that rainfall is generally decreasing. Climate variation poses a number of problems which hinder agricultural production in Jakiri Sub-Division. Some of these problems are highly felt while others are not considered as a threat to agriculture by farmers may be because their manifestation is not really felt. The highest problem faced by farmers is water scarcity during the dry season, declining soil fertility, deforestation, inadequate grazing land, while early onsets rain and pest and insect attach is what farmers consider to be a rare problem. The drivers that cause more problems to agricultural production in Jakiri SubDivision as perceived by farmers are the late onset of the first rains, plant diseases, floods, soil infertility, lack of pesticides, wind hazards, deforestation, competition of arable land with graziers and water scarcity. Minor drivers are early onset of the first rains, persisting droughts after the first rains, insect pests, soil erosion, inadequate farming land, lack of fertilizers and bush fires. Other control factors such, temperature as relief and anthropogenic factors come into play. This explains reason why there is just a slight increase in both food and cash crop in the entire Sub-Division. A crop like cassava has proven to be resilient to changing climatic and environmental conditions in Jakiri Sub-Division and it production should be encouraged. The three agro-ecological zones of production require to embarked on proactive and reactive adaptive measure to further increased general crop outputs or the trend might easily be negative in the nearest future if quick measure to improve on agricultural activity with variation in rainfall patterns is not taken. Production of more drought tolerant food crops for the sustenance of rural livelihoods. If these measures are taken, then Jakiri SubDivision will be on the right path to achieving food security in line with SDG-2 and proactive to combat climate change and its impacts at the local level (SDG-13).

\section{References}

1. Shames S, Scherr SJ, De Pinto A, Ringler C, Cenacchi N, et al. (2019) Food security and livelihoods of small-scale producers. Adapt now: A global call for leadership on climate resilience. Global Centre on Adaptation and World Resources Institute, New York, USA, pp: 23-29.

2. Intergovernmental Panel on Climate Change-IPCC (2019) Special report on climate change, desertification, land degradation, sustainable land management, food security, and greenhouse gas fluxes in terrestrial ecosystems. IPCC Secretariate, Bonn, Germany, pp: 1-35.

3. Feenstra JF, Burton I, Smith JB, Tol RSJ (1998) Handbook on methods for climate change impact assessment and adaptation strategies. UNEP \& Vrije Universiteit Amsterdam, Netherlands.

4. Tume SJP, Zetem CC, Nulah SM, Ateh EN, Mbuh BK, et al. (2020) Climate change and food security in the bamenda highlands of Cameroon. In: Squires VR, Mahesh K, Gaur MK (Eds.), Food Security and Land Use Change under Conditions of Climate Variability: A Multidimensional Perspective. Springer Cham, Berlin, Germany, pp: 107-124.
5. Hulme M, Doherty R, Ngara T, New M (2005) Global warming and African climate: a reassessment. In: Low PS, Climate Change and Africa. Cambridge University Press, UK, pp: 29-40.

6. Intergovernmental Panel on Climate Change-IPCC (2007) Climate change 2007: Impacts, adaptation and vulnerability. Contribution of Working Group II to the Fourth Assessment Report of the Intergovernmental Panel on Climate Change. Cambridge University Press, Cambridge, UK, p. 976.

7. Toulmin C, Huq S (2006) Sustainable development: africa and climate change. International Institute for Environment and Development, London, pp: 1-2.

8. Tume SJP, Kimengsi JN, Fogwe ZN (2019) Indigenous knowledge and farmer perceptions of climate and ecological changes in the Bamenda highlands of Cameroon: Insights from the Bui Plateau. Climate 7(12): 138.

9. Campbell B, Mann W, Meléndez Ortiz R, Streck, C, Tennigkeit T, et al. (2011) Agriculture and climate change: A scoping report. Meridian Institute, Bangkok, p. 98.

10. McSweeney C, New M, Lizcano G (2012) UNDP climate change country, Profiles-Cameroon. School of Geography and Environment, University of Oxford, England, pp: 7-8.

11. Tume SJP (2019) Standardised precipitation valuation of water resources vulnerability to climate variability on the Bui Plateau, Northwest Cameroon. Environment and Ecology Research 7(2): 83-92.

12. Tume SJP, Tani BV (2018) Stakeholders' signature to climate change adaptation in the agrarian sector of Bui Plateau, Northwest Cameroon. Journal of Environmental Issues and Agriculture in Developing Countries, 10(3): 140-156.

13. Tani BV, Tume SJP (2019) The role of municipal councils in climate change mitigation the Northwest Region of Cameroon. International Journal of Resource and Environmental Management. Unique Printers, Bamenda, Cameroon, 4(2): 3-17.

14. World Meteorological Organization (WMO) and Global Water Partnership (GWP) (2016) Handbook of drought indicators and indices. Integrated Drought Management Programme (IDMP), Integrated Drought Management Tools and Guidelines Series 2, Geneva, Switzerland, p. 45.

15. Tume SJP, Fogwe ZN (2018) Standardised precipitation index valuation of crop production responses to climate variability on the Bui Plateau, Northwest Region of Cameroon. Journal of Arts and Humanities, Faculty of Arts, The University of Bamenda, Cameroon, 1(2): 21-38.

16. Eriksen S (2005) The role of indigenous plants in household adaptation to climate change: the Kenyan experience. In: Low PS, Climate Change and Africa. Cambridge University Press, UK, pp: 248-259.

17. Obasi GOP (2005) The impacts of ENSO in Africa. In: Low PS, Climate Change and Africa. Cambridge University Press, UK, p. 226.

18. Mairomi HW, Tume SJP (2021) Standardized precipitation index valuation of seasonal transitions and adaptation of pastoralist to climate variability in rangelands of the Bamenda highlands of Cameroon. Journal of Ecology \& Natural Resources 5(1): 000229.

19. Zilberman D (2018) Conclusion and policy implication to climate smart agriculture: Building resilience to climate change. In: Lipper L, McCarthy N, Zilberman D, Asfaw S, Branca G (Eds.), Climate Smart Agriculture: Building Resilience to Climate Change. FAO and Springer cham, Berlin, Germany, pp: 421-426.

20.Zilberman D, Lipper L, McCarthy N, Gordon B (2018) Innovation in response to climate change. In: Lipper L, McCarthy N, Zilberman D, Asfaw S, Branca G, (Eds.), Climate Smart Agriculture: Building Resilience to Climate Change. FAO and Springer Cham, Berlin, Germany, pp: 49-76.

21. Collier P, Conway G, Venables T (2008) Climate change and Africa. Oxford Review of Economic Policy 24(2): 337-353. 
22. Sivakumar M, Das H, Brunini O (2005) Impacts of present and future climate variability and change on agriculture and forestry in the arid and semi-arid tropics. Climatic Change 70: 31-72.

23. Agba DZ, Adewara SO, Adama JI, Adzer KT, Atoyebi GO (2017) Analysis of the effects of climate change on crop output in Nigeria. American Journal of Climate Change 6(3): 554-571.

24. Blanc E (2012) The impact of climate change on crop yields in SubSaharan Africa. American Journal of Climate Change 1(1): 1-13.

25. Tume SJP, Kongnso ME, Nyukighan MB, Dindze NE, Njodzeka GN (2018) Stakeholders in climate change communication in the northwest region of Cameroon. In: Tume SJP, Tanyanyiwa VI (Eds.), Climate Change Perception and Changing Agents in Africa \& South Asia, Vernon Press, Wilmington, Delaware, USA, pp: 97-116.

26. Ajiere SI, Weli VE (2018) Assessing the impact of climate change on maize (Zea mays) and cassava (Manihot esculenta) yields in rivers state, Nigeria. Atmospheric and Climate Sciences 8(2): 274-285.

27. Tall A, Lynagh S, Vecchi CB, Bardouille P, Pino FM, et al. (2021) Enabling private investment in climate adaptation and resilience: current status, barriers to investments and blueprint for action. World Bank and Global Facility for Risk Reduction and Recovery, p. 70.

For possible submissions Click below: 